\title{
LIPOMATOSIS OF SKELETAL MUSCLE IN MAFFUCCI'S SYNDROME
}

\author{
(Dyschondroplasia with Haemangiomata)
}

\author{
A. H. Cameron and D. H. McMillan, Sheffield, England \\ From the Department of Pathology, University of Sheffield, \\ and Department of Orthopaedics, Sheffield Royal Infirmary
}

The association of dyschondroplasia with angiomata was first described by Maffucci (1881). In 1942 Carleton, Elkington, Greenfield and Robb-Smith compiled a comprehensive review of eighteen reported cases and gave a detailed description of two additional cases. They suggested that the syndrome be associated with the name of Maffucci. Further examples have since been recorded by Krause (1944), Umansky (1946) and Strang and Rannie (1950), making a total of twenty-three published cases up to the present time.

Gross deformity associated with multiple chondromatous and angiomatous tumours has been a feature of the previously reported cases, but in our patient there has so far appeared only a single chondroma, and angiomata of skeletal muscle, subcutaneous tissue and periarticular tissue. A distinctive feature in our case was a tumour-like adipose infiltration of the semitendinosus muscle and short head of biceps femoris.

\section{CASE REPORT}

The patient, a boy, was born in May 1944 and was normal in all respects until the age of four years. His parents were not consanguineous, and there was no significant clinical history related to them or their one other child. A swelling was noticed by the mother on the medial aspect of the patient's right knee at the age of four. It was not painful, but was a little tender on pressure. The mass was excised, and histological examination proved it to be a haemangioma. The wound healed uneventfully.

However, a tense, firm tumour, about five centimetres in diameter, recurred at the same site two years later. At operation a cartilaginous mass was seen to arise from the tibial epiphysis. It was necessary to open the joint cavity in order to remove the tumour completely. The tumour histologically was a chondroma with angiomata in the periarticular tissues. The wound healed uneventfully.

Within four weeks the mother believed that there was a further swelling in the muscles of the back of the right thigh. Clinical examination revealed a slight flexion deformity of the knee but no tumour. The patient fell on the right knee eighteen months later, and the joint was then found to be irritable, and flexion severely limited. There was no radiological evidence of fracture. After the joint had been rested in a Thomas's splint for four weeks the acute condition subsided, but there was a fixed flexion deformity of 45 degrees. In February 1955, when the child was nearly eleven, a hard mass in the posterior thigh muscles was clearly palpable. At operation the tumour appeared to occupy the whole length of the semitendinosus muscle and the short head of the biceps femoris. There was some fibrosis of the surrounding connective tissue but no involvement of the sciatic nerve or other surrounding structures. The semitendinosus and short head of biceps were excised and the wound healed uneventfully. After the operation the range of movement of the joint improved, and after four months is now from 45 to 10 degrees. No further haemangiomata, chondromata or other abnormalities have been revealed by careful clinical and radiological examination.

Pathological features-The first tumour removed from the right knee-Two small blocks were available for histological examination. In both there were numerous rounded angiomatous nodules ranging from one to four millimetres in diameter (Fig. 1). Each nodule consisted 
of a circumscribed mass of myxomatous fibrous tissue containing angiomatous vessels. The vessels resembled thick-walled capillaries with a prominent endothelial lining and sometimes without a lumen, but many were wider sinusoidal spaces filled with blood. Muscular arteries either within the nodules or in the closely adjacent tissues, showed marked fibro-elastic thickening of the intima. Macrophages contained a little haemosiderin.

The chondroma from the right knee-The block of tissue available for histological examination included a crescentic portion of the tumour, part of the joint cavity and the surrounding connective tissue. The tumour was a simple chondroma consisting of hyaline cartilage, with a well defined margin bounded by a fibrous capsule or perichondrium. That part of the tumour which extended into the joint cavity was covered by a thin layer of synovial tissue as well as by a thin layer of fibrous tissue continuous with the thicker perichondral capsule.

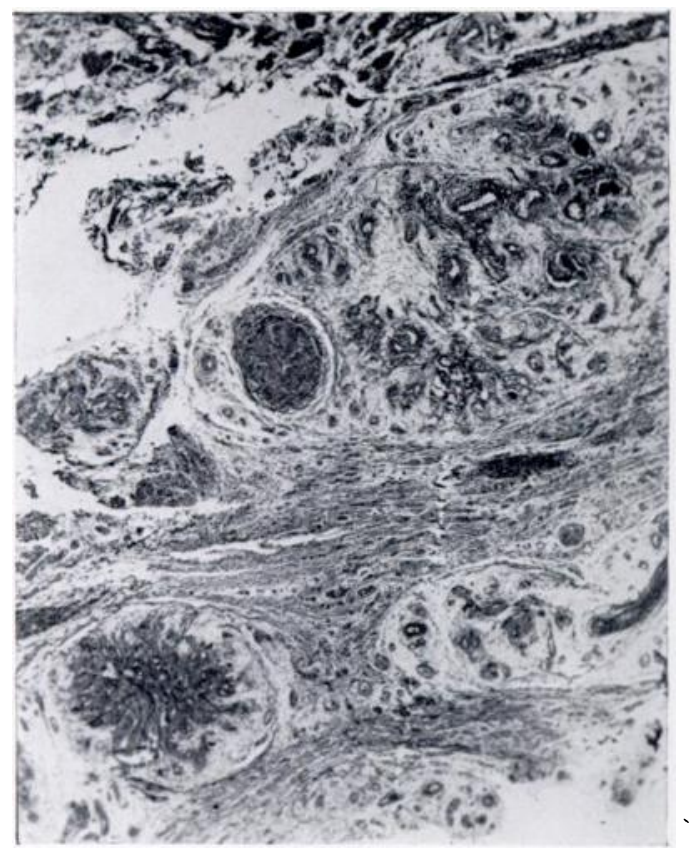

Fig. 1

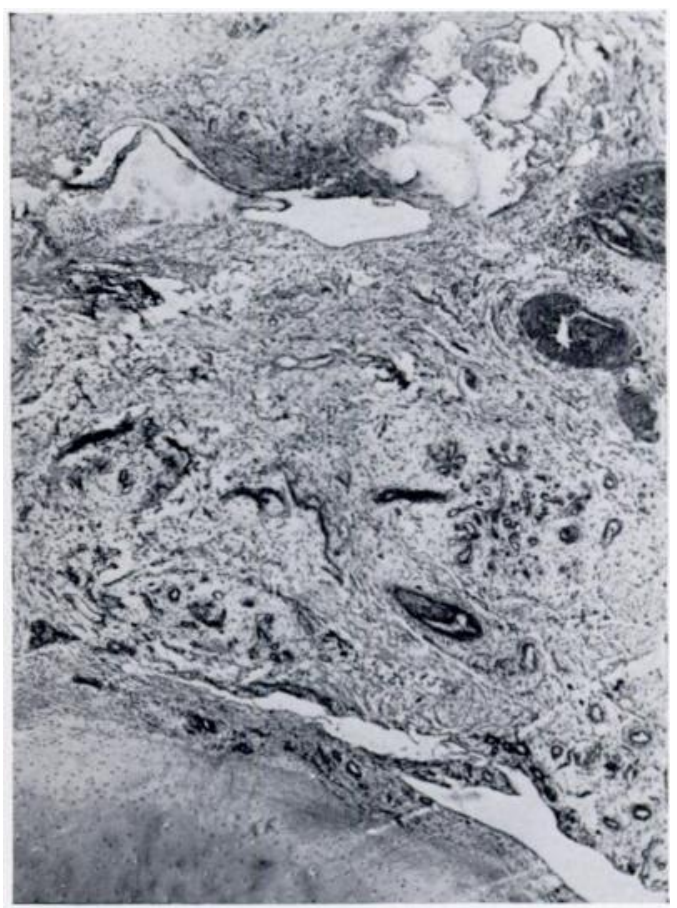

FIG. 2

Figure 1-Angiomatous capillary vessels in pale rounded nodules of myxomatous fibrous tissue. Towards the centre is an artery with narrowing of the lumen from endarteritis obliterans. (Haematoxylin and Van Gieson, 18.) Figure 2-Capillary and cavernous angiomatous tissue in the periarticular tissues. A thickened artery lies to the right. Part of the chondroma and synovial membrane are seen below. (Haematoxylin and eosin, $\times 17$.

The part of the synovial membrane reflected from the surface of the tumour appeared moderately oedematous and vascular. The attached periarticular tissues contained several capillary angiomata like those in the first tumour, and also two cavernous haemangiomata with thin-walled sinusoidal spaces surrounded by a moderate amount of fibrous connective tissue containing a little plain muscle (Fig. 2). A moderate amount of haemosiderin was found in macrophages in the surrounding connective tissue. Several related muscular arteries showed marked fibro-elastic thickening of the intima.

Semitendinosus muscle and short head of biceps femoris-The semitendinosus muscle was represented by a firm fusiform mass, twenty-five centimetres long and seven centimetres in diameter, invested by a thin fibrous fascia. It consisted mainly of compact, firm adipose tissue in elliptical compartments separated by thin fibrous septa. A broad tendinous structure was included near one end, but there was otherwise little resemblance to skeletal muscle

vol. 38 B, No. 3, AUgust 1956

$\mathrm{Fl}_{1+1}$ 
(Fig. 3). It contained many blood vessels with a varicose appearance, some of which were cut in longitudinal section for a distance of about three centimetres. Examination with a hand lens revealed that they consisted of compact aggregations of many small blood-filled spaces. The short head of biceps femoris measured eight centimetres in length and three centimetres in diameter, and had a similar appearance, but it more closely resembled skeletal muscle and appeared to contain less fat. Radiological examination of the specimens showed no opacities suggestive of phleboliths. Histological examination showed that the muscle compartments were almost entirely replaced by adipose tissue. The fibrous-tissue septa of

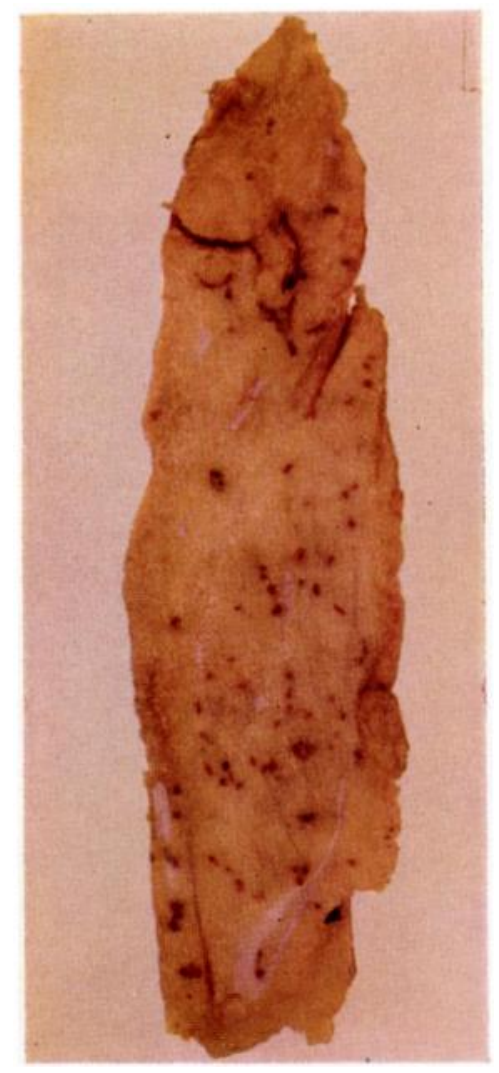

Fig. 3

The semitendinosus muscle consists chiefly of adipose tissue and contains many small angiomata. Some are cut in longitudinal section towards the top of the specimen, and at the opposite end there is a broad tendinous structure.

perimysium were increased in thickness and moderately oedematous. There were many discrete angiomata throughout the tissue, most of them about 0.25 centimetre across (Fig. 4). Each comprised a group of cavernous blood spaces, usually situated close to a muscular artery of medium size, and enveloped in a varying amount of plain muscle and fibrous connective tissue. The spaces were filled with blood and had generally a prominent endothelial lining. In many instances there were traces of an elastic lamina surrounding the angiomata, and occasionally it was intact round the whole circumference, an appearance suggesting phlebectasia (Fig. 5). Sometimes the walls of the angiomata contained vasoformative tissue showing budding endothelial tubes with or without a lumen. Thrombi were not seen in the angiomata, but occasionally haemosiderin was found in the surrounding connective tissue. 
Relatively normal veins were seldom seen in relation to these lesions, whereas muscular arteries, often showing obliterative endarteritis, were almost constantly present.

The voluntary muscle bundles were everywhere severely atrophied. Surviving fibres were few and widely separated one from another by adipose tissue. They were more numerous close to the thickened perimysial bands (Fig. 6). Most of the striped muscle fibres were between $8 \mu$ and $15 \mu$ in diameter, but individual fibres near the perimysium measured up to about $80 \mu$ in diameter. Cross striation was preserved in most of the atrophic fibres (Fig. 7) but not infrequently pale, rounded, hyaline, and degenerated fibres were encountered with numerous sarcolemmal nuclei around them or within the substance of the fibre (Fig. 8). There was a little irregular lymphocytic infiltration and fibrosis of the endomysium, and some

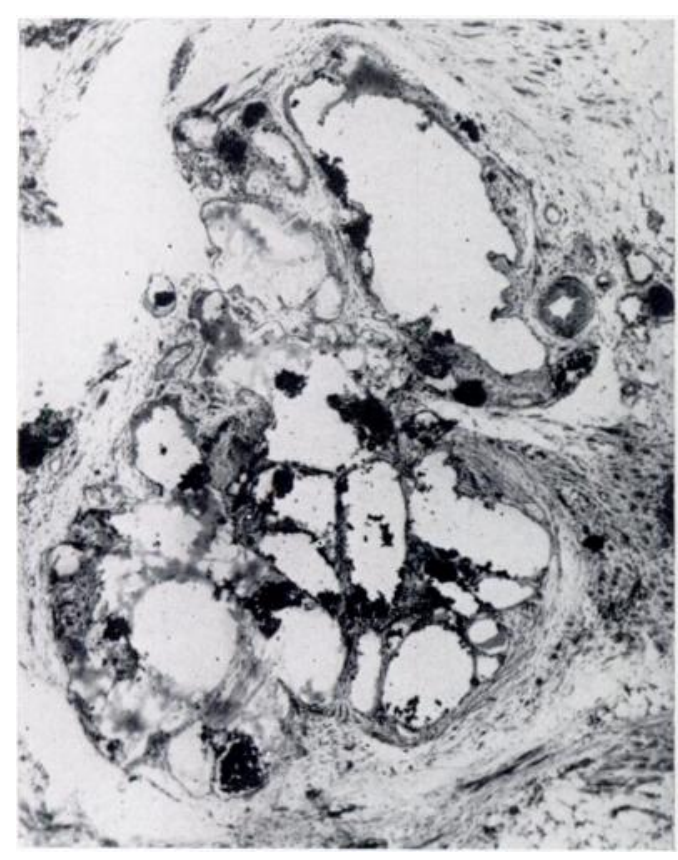

FIG. 4

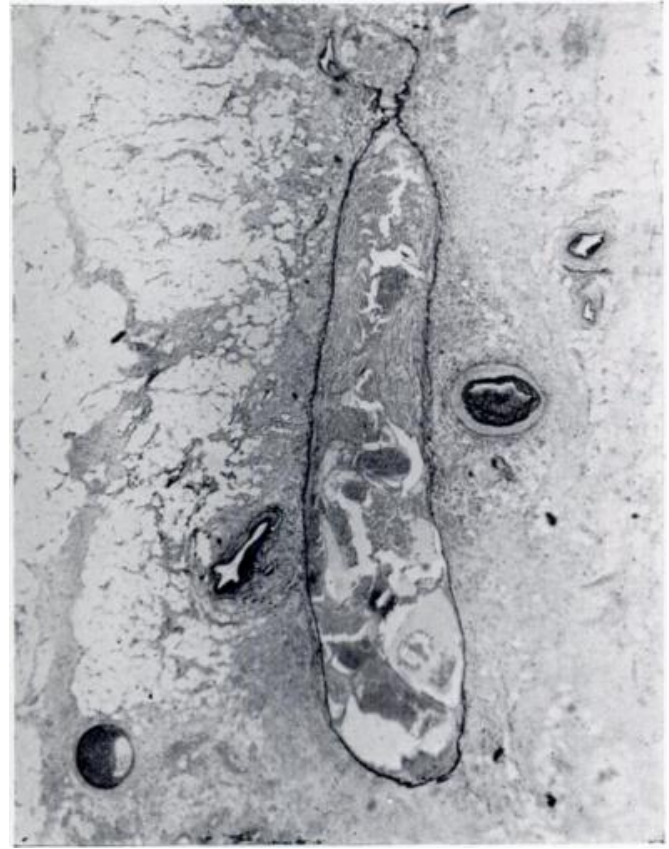

Fig. 5

Figure 4-A cavernous angioma in the wall of which there is a small artery showing endarteritis obliterans. (Haematoxylin and eosin, $\times 36$.) Figure 5-A phlebectactic vein resembling an angioma. It is surrounded by an intact elastic lamina and the lumen is intersected by fibro-elastic tissue. Adjacent muscular arteries show endarteritis obliterans of varying degree. (Weigert's elastin stain and Safranin, $\times 18$.)

fibrous thickening of the walls of the smaller endomysial blood vessels. Follicular aggregates of lymphocytes were frequent, often several being encountered in a cross-section of a single atrophic muscle bundle.

\section{DISCUSSION}

Multiple chondromata and angiomata, with a tendency towards unilateral distribution, are the characteristic features of Maffucci's (1881) syndrome. The tumours usually appear during post-natal development and often cease to progress after puberty. The tumours that have so far appeared in our patient were limited to the right lower limb, and in our opinion this is a relatively mild case of the syndrome. Carleton et al. (1942) suggested that mild cases such as this might be overlooked and that further examples might be recognised if the manifestations of the syndrome were searched for in every patient with chondromata or angiomata. The findings of Umansky (1946), however, are not encouraging in this respect. He was able to find no instances of the syndrome, and no association of the two lesions, in sixty-five cases of dyschondroplasia and seventy-one cases of haemangiomata.

vol. 38 B, NO. 3, AUgust 1956

F2, 81 
An important feature in our case was the angiomatous involvement of the semitendinosus muscle and short head of biceps. In most of the reported cases of Maffucci's syndrome the angiomata were soft purple tumours in the subcutaneous tissues, but in some they were deep-seated and extended down to bone. None appeared to originate primarily in muscle as in this case.

Skeletal muscle is a not uncommon site for angiomata. Jones (1953) found records of 358 cases in the literature and described fourteen further cases. They form only a small proportion of haemangiomata in general (Watson and McCarthy 1940), but according to Weaver (1938) most deep-seated angiomata of the lower extremities do arise in muscle. A total of 212 cases of angiomata in muscle, including eleven new cases of their own, were analysed by Davis and Kitlowski (1930), and they emphasised that the tumours were usually

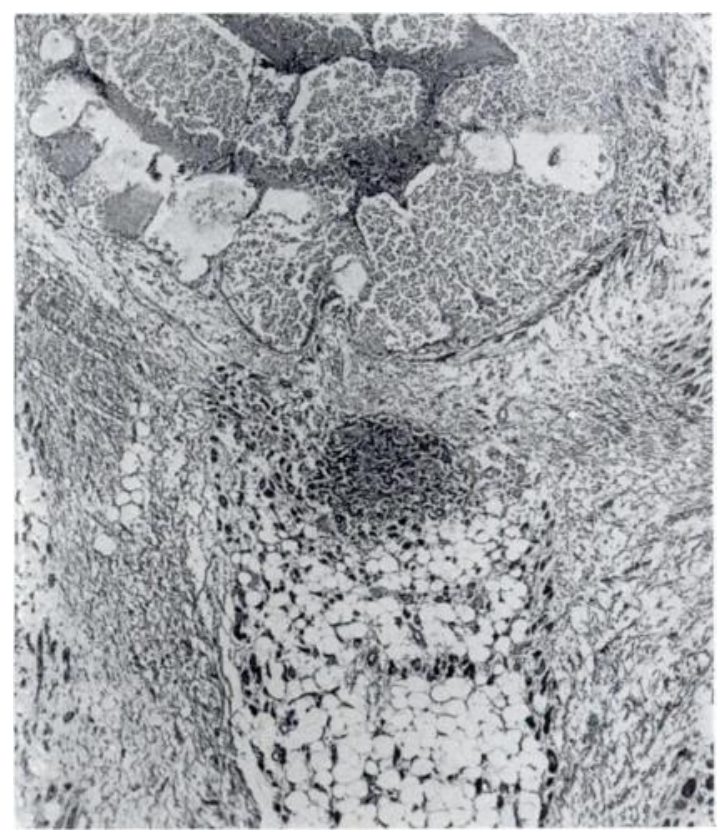

FIG. 6

A section from semitendinosus muscle showing part of a cavernous angioma. A muscle bundle, lying between two thickened perimysial septa, is almost completely replaced by adipose tissue and most of the surviving muscle fibres lie close to the perimysium. In the centre of the field there is a follicular aggregation of lymphocytes. (Mallory's phosphotungstic acid haematoxylin, $\times 50$.)

infiltrative, poorly circumscribed, cavernous haemangiomata, the muscle often seeming to contain multiple varicose veins, just as in the present case. Adipose tissue replacement of the muscle in the vicinity of the angiomata was frequently noted, and in two cases (Cases 2 and 7) of Davis and Kitlowski, approached in extent that observed in the present instance.

The adipose enlargement of the involved muscles in the present case was so pronounced as to give a misleading clinical impression of actual tumour. The angiomata in the muscle were in themselves little responsible for the swelling. The adiposity of the muscle appeared, as in pseudohypertrophic muscular dystrophy, to be secondary to marked atrophy of the muscle fibres. There was also considerable shortening of the muscles and flexion deformity of the knee, perhaps attributable to the perimysial and endomysial fibrosis observed histologically. Although atrophy and fibrosis of muscle have been found to follow disuse in dogs (Tower 1937, Reid 1941), only simple atrophy of muscle fibres is observed under similar conditions in 
man (Adams, Denny-Brown and Pearson 1953), and the marked muscular atrophy and interstitial proliferation observed in the present case are not likely to be simply the result of splintage and disuse. Apart from the angiomata the pathological changes in the muscle are similar to those observed in the later stages of pseudohypertrophic muscular dystrophy. But there was no clinical evidence of a coexistent primary muscular dystrophy in this case, nor was there a family history of such a disorder. Especially in view of the similar fatty replacement in the two cases of angiomata in skeletal muscle described by Davis and Kitlowski (1930), we believe that the muscular atrophy and secondary adiposity and fibrosis must be directly connected with the angiomatous lesions present throughout the muscle mass. In our opinion these angiomata constituted multiple arterio-venous shunts and the resulting tissue anoxia was responsible for the pathological changes observed in the muscle. In fatty degeneration

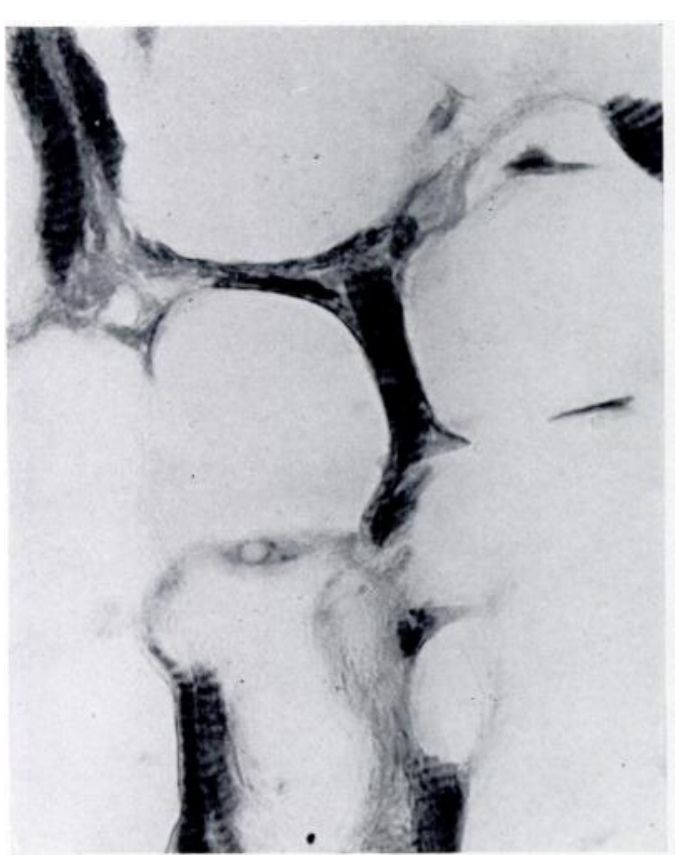

Fig. 7

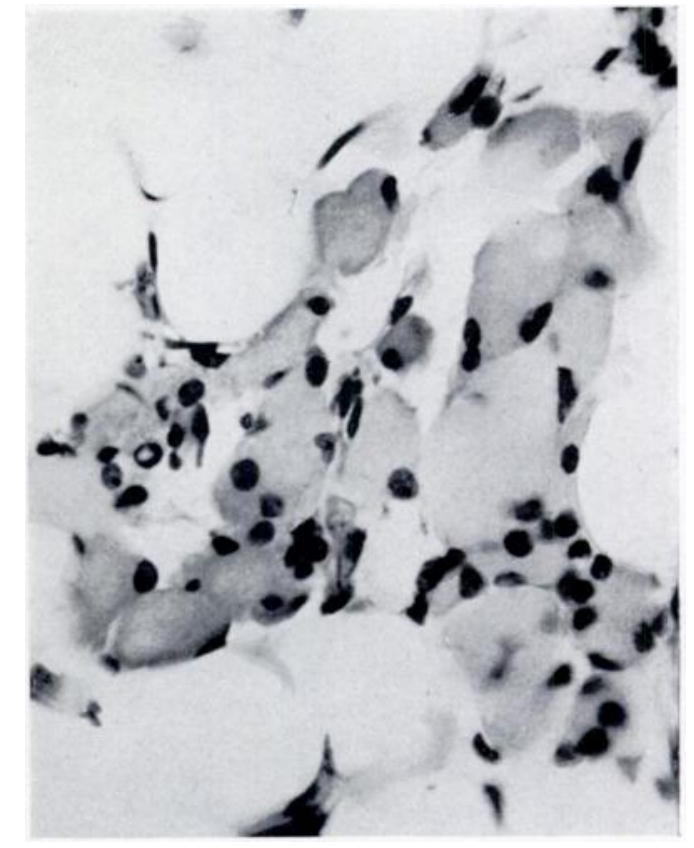

FIG. 8

Figure 7-Semitendinosus muscle. Atrophic muscle fibres, approximately $10 \mu$ in diameter, with intact cross striation. The muscle fibres are separated by adipose tissue. (Mallory's phosphotungstic acid haematoxylin, $\times 580$.) Figure 8 -Semitendinosus muscle. Pale swollen, hyaline and degenerate fibres with numerous sarcolemmal nuclei. (Haematoxylin and eosin, $\times 440$.)

of heart muscle in anaemic anoxia the muscle fibres farthest away from the blood supply are the most severely affected. Similarly, in the case under discussion, the central fibres of the muscle bundles showed the most severe atrophy, whereas the peripheral muscle fibres, nearer the perimysium and its blood vessels, were relatively well preserved.

The local anoxia arising in this way would be persistent and of low grade, whereas most of the recorded experimental observations relevant to muscle ischaemia involve acute, and usually massive, vascular obstruction. Brooks (1922) produced severe fibrosis of skeletal muscle by venous obstruction and Griffiths (1940), by arterial obstruction, produced focal necrosis of muscle surrounded by a zone of fibrogranulation tissue. Both these authors considered those different pathological changes to be the essential pathological feature of the cases of Volkmann's ischaemic contracture they described. The pathological changes in the muscle observed in the present case do not resemble those described by either Brooks or Griffiths, and we consider that they are the result of persistent low-grade anoxia. 


\section{SUMMARY}

A boy aged eleven with a solitary chondroma of the right tibia, and angiomata of the skeletal muscle, subcutaneous tissues, and periarticular tissues of the same limb, is considered to be a case of Maffucci's syndrome (dyschondroplasia with angiomata), although there was not the severe deformity encountered in the previously reported cases. There was a secondary atrophy and adiposity of skeletal muscle, and this was attributed to anoxic effects produced by the angiomata.

We wish to thank Mr F. W. Holdsworth and Professor D. H. Collins for much helpful advice in preparing this paper, and also Dr A. J. N. Warrack of the Sheffield City General Hospital for allowing us to use biopsy material from his laboratory.

\section{REFERENCES}

Adams, R. D., Denny-Brown, D., and Pearson, C. M. (1953): Diseases of Muscle, p. 204. London: Cassell \& Company Ltd.

Brooks, B. (1922): Pathologic Changes in Muscle as a Result of Disturbances of Circulation. Archives of Surgery, 5, 188.

Carleton, A., Elkington, J. St C., Greenfield, J. G., and Robb-Smith, A. H. T. (1942): Maffucci's Syndrome (Dyschondroplasia with Haemangiomata). Quarterly Journal of Medicine, N.S. 11, 203.

Davis, J. S., and Kitlowski, E. A. (1930): Primary Intramuscular Hemangiomas of Striated Muscle. Archives of Surgery, 20, 39.

GRIfFITHS, D. Ll. (1940): Volkmann's Ischaemic Contracture. British Journal of Surgery, 28, 239.

JoNes, K. G. (1953): Cavernous Hemangioma of Striated Muscle. Journal of Bone and Joint Surgery, 35-A, 717. KraUSE, G. R. (1944): Dyschondroplasia with Haemangiomata (Maffucci's Syndrome). American Journal of Roentgenology, 52, 620.

Maffucci, A. (1881): Di un caso encondroma ed angioma multiple. Movimento medico-chirurgico, 2s. 3, 399, quoted by Carleton, A., Elkington, J. St C., Greenfield, J. G., and Robb-Smith, A. H. T. (1942): Maffucci's Syndrome. Quarterly Journal of Medicine, N.S. 11, 203.

ReID, G. (1941): A Comparison of the Effects of Disuse and Denervation upon Skeletal Muscle. Medical Journal of Australia, ii, 165. Quoted by Adams, R. D., Denny-Brown, D., and Pearson, C. M. (1953): Diseases of Muscle, p. 127. London: Cassell \& Company Ltd.

Strang, C., and RanNie, I. (1950): Dyschondroplasia with Haemangiomata (Maffucci's Syndrome). Journal of Bone and Joint Surgery, 32-B, 376.

Tower, S. S. (1937): Trophic Control of Non-Nervous Tissues by the Nervous System: A study of Muscle and Bone Innervated from an Isolated and Quiescent Region of Spinal Cord. Journal of Comparative Neurology, 67, 241. Quoted by Adams, R. D., Denny-Brown, D., and Pearson, C. M. (1953): Diseases of Muscle, p. 127. London: Cassell \& Company Ltd.

UMANSKy, A. L. (1946): Dyschondroplasia with Hemangiomata (Maffucci's Syndrome). Bulletin of the Hospital for Joint Diseases, 7, 59. Quoted by Strang, C., and Rannie, I. (1950): Dyschondroplasia with Haemangiomata (Maffucci's Syndrome). Journal of Bone and Joint Surgery, 32-B, 376.

Watson, W. L., and McCarthy, W. D. (1940): Blood and Lymph Vessel Tumors. A Report of 1,056 Cases. Surgery, Gynecology and Obstetrics, 71, 569.

WeAVer, J. B. (1938): Hemangiomata of the Lower Extremities with Special Reference to those of the KneeJoint Capsule and the Phenomenon of Spontaneous Obliteration. Journal of Bone and Joint Surgery, 20, 731. 